\title{
Effects of the Brain-Derived Neurotrophic Growth Factor Val66Met Variation on Hippocampus Morphology in Bipolar Disorder
}

\author{
Lara G Chepenik*,1,2, Carolyn Fredericks' ${ }^{1,3}$, Xenophon Papademetris ${ }^{4}$, Linda Spencer ${ }^{1,2}$, Cheryl Lacadie ${ }^{4}$, \\ Fei Wang ${ }^{1,2}$, Brian Pittman', James S Duncan ${ }^{4}$, Lawrence H Staib ${ }^{4}$, Ronald S Duman', Joel Gelernter ${ }^{1,2}$ \\ and Hilary P Blumberg ${ }^{1,2,4}$
}

'Deparment of Psychiatry, Yale University School of Medicine, New Haven, CT, USA; ${ }^{2}$ Department of Psychiatry, Veterans Affairs Connecticut Healthcare System, West Haven, CT, USA; ${ }^{3}$ Stanford University School of Medicine, Stanford, CA, USA; ${ }^{4}$ Department of Diagnostic Radiology, Yale University School of Medicine, New Haven, CT, USA

\begin{abstract}
Histological and behavioral research in bipolar disorder (BD) implicates structural abnormalities in the hippocampus. Brain-derived neurotrophic growth factor (BDNF) protein is associated with hippocampal development and plasticity, and in mood disorder pathophysiology. We tested the hypotheses that both the BDNF val66met polymorphism and BD diagnosis are associated with decreased hippocampus volume, and that individuals with $\mathrm{BD}$ who carry the met allele have the smallest hippocampus volumes compared to individuals without BD and val/val homozygotes. We further explored localization of morphological differences within hippocampus in BD associated with the met allele. Twenty individuals with BD and 18 healthy comparison (HC) subjects participated in high-resolution magnetic resonance imaging scans from which hippocampus volumes were defined and measured. We used linear mixed model analysis to study effects of diagnosis and BDNF genotype on hippocampus volumes. We then employed three-dimensional mapping to localize areas of change within the hippocampus associated with the BDNF met allele in BD. We found that hippocampus volumes were significantly smaller in $\mathrm{BD}$ compared to $\mathrm{HC}$ subjects, and presence of the BDNF met allele was associated with smaller hippocampus volume in both diagnostic groups. The BD subgroup who carried the BDNF met allele had the smallest hippocampus volumes, and three-dimensional mapping identified these decreases as most prominent in left anterior hippocampus. These results support effects of BD diagnosis and BDNF genotype on hippocampus structure and suggest a genetic subgroup within BD who may be most vulnerable to deficits in hippocampus and may most benefit from interventions that influence BDNF-mediated signaling. Neuropsychopharmacology (2009) 34, 944-95I; doi: I0. I038/npp.2008. 107; published online 13 August 2008
\end{abstract}

Keywords: bipolar disorder; brain-derived neurotrophic growth factor, BDNF gene; hippocampus; magnetic resonance imaging; single nucleotide polymorphism

\section{INTRODUCTION}

Histological and molecular studies in bipolar disorder (BD) consistently demonstrate cellular abnormalities within hippocampus. Postmortem studies report decreased hippocampal cell number and density in BD (Benes et al, 1998; Bielau et al, 2005; Chambers and Perrone-Bizzozero, 2004; Rosoklija et al, 2000), and magnetic resonance spectroscopy studies demonstrate reduced levels of $\mathrm{N}$-acetylaspartate, a putative marker for neuronal integrity, in the hippocampus of $\mathrm{BD}$ patients relative to healthy comparison (HC) subjects

*Correspondence: Dr LG Chepenik, Department of Psychiatry, Yale University School of Medicine, 300 George Street, Suite 901, New Haven, CT 65 I I, USA, Tel: + I 203785 6394, Fax: + I 20373725 I3, E-mail: lara.chepenik@yale.edu

Received 5 April 2008; revised 30 May 2008; accepted 8 June 2008
(Bertolino et al, 2003; Deicken et al, 2003). Abnormal levels of biochemical markers related to neuronal sprouting and plasticity (Dowlatshahi et al, 2000; Fatemi et al, 2001; MacDonald et al, 2006), cell signaling (Law and Deakin, 2001), and oxidative metabolism (Konradi et al, 2004) have also been observed in the hippocampus in $\mathrm{BD}$.

Consistent with cellular evidence for hippocampal pathology, there is convergent behavioral data supporting hippocampal dysfunction in BD. Impaired performance on tests of episodic verbal memory, a measure of hippocampal function, is one of the most frequently reported cognitive deficits in BD (Cavanagh et al, 2002; Clark et al, 2001; Deckersbach et al, 2004; Glahn et al, 2005; Pavuluri et al, 2006; van Gorp et al, 1999; Wolfe et al, 1987). These deficits are present in children and adults with $\mathrm{BD}$, and across mood states. Their presence in youth, during euthymic periods (Clark et al, 2001; Sweeney et al, 2000; van Gorp 
et al, 1999; Wolfe et al, 1987), and in unaffected monozygotic twins of $\mathrm{BD}$ patients and non-twin siblings of patients with BD (Gourovitch et al, 1999; Keri et al, 2001) suggests hippocampal dysfunction may reflect an underlying vulnerability for BD.

Despite these observations, morphometric imaging studies of hippocampus in BD fail to provide consistent evidence of decreased volume. Several studies demonstrate significant decreases in the volume of gray matter in individuals with BD compared to HC patients (Frazier et al, 2005; Hauser et al, 1989; Noga et al, 2001; Strasser et al, 2005; Swayze et al, 1992). However, other studies report only a trend toward smaller hippocampus volume in BD (Blumberg et al, 2003; Brambilla et al, 2003), or no difference between BD and HC groups (Altshuler et al, 2000; Chang et al, 2005; Chen et al, 2004a; Hauser et al, 2000; Strakowski et al, 1999). Variability in these findings may reflect the presence of hippocampal deficits only within particular demographic or clinical subgroups as age, sex, and presence of psychotic symptoms have all been associated with variability in hippocampal volume in BD (Blumberg et al, 2003; Chambers and PerroneBizzozero, 2004; Frazier et al, 2005; Sax et al, 1999; Strasser et al, 2005; Velakoulis et al, 1999). It is also possible that studies may vary in the proportion of individuals within the samples carrying different polymorphic variants in genes associated with hippocampus morphology.

Cellular studies suggest brain-derived neurotrophic growth factor (BDNF) has the potential to influence hippocampus morphology in BD. BDNF promotes neuron growth and synapse formation (Maisonpierre et al, 1990; Thoenen, 1995) and low BDNF levels are implicated in hippocampal deficits in animal models of mood disorders (Chen et al, 2001; Duman and Charney, 1999; Duman et al, 1997; Nibuya et al, 1995; Santarelli et al, 2003). Decreased levels of BDNF protein have since been detected peripherally during depressed and manic episodes, and in brain tissue in postmortem studies of BD (Cunha et al, 2006; Knable et al, 2004; Neumeister et al, 2005). In addition, research in rodents shows medications used to treat BD increase neural BDNF levels (Bennett et al, 2000; Hashimoto et al, 2002), including specific increases within hippocampus (Frey et al, 2006; Fukumoto et al, 2001).

The val66met BDNF polymorphism is a functional variation associated with deficiencies in intracellular trafficking and activity-dependent release of $B D N F$ protein (Chen et al, 2004b; Egan et al, 2003). This allele is also associated with impaired episodic memory, decreased hippocampus recruitment and decreased hippocampus volume in HC groups, major depression, and schizophrenia (Bueller et al, 2006; Frodl et al, 2007; Hariri et al, 2003; Pezawas et al, 2004; Szeszko et al, 2005). In this study we tested the hypotheses that the BDNF val66met variant would influence hippocampus volumes in both $\mathrm{HC}$ and BD study groups, and individuals with $\mathrm{BD}$ who carry at least one copy of the met allele ( val/met or met/met genotype) would have the smallest hippocampus volumes compared to BD val/val homozygotes and HC subjects. We also employed a technique to evaluate three-dimensional (3D) hippocampus maps in an effort to localize the areas of change within hippocampus in BD most strongly associated with the $B D N F$ val66met polymorphism.

\section{METHODS}

\section{Subjects}

Subjects included 20 adults with BD (11 female patients: age 21-56 years; race: 18 European Americans; 2 other) and 18 HC participants ( 12 female patients: age $18-58$ years; race: 13 European Americans; 3 African Americans; 2 other). Subjects with BD included $12 \mathrm{val} / \mathrm{val}$ homozygotes and 8 'met carriers' (seven individuals heterozygous for the met allele and one met/met homozygote). In the HC group, 12 subjects were homozygous for the val allele and 6 subjects were met carriers (all heterozygous for the met allele). Study participants were recruited through the Veterans Affairs Connecticut Health Care System, West Haven; the Yale School of Medicine, New Haven, CT; and practitioners in the community or from advertisement in local newspapers. All subjects provided written, informed consent for participation in this study protocol as approved by the Yale School of Medicine and Department of Veterans Affairs institutional review boards.

Presence or absence of DSM-IV Axis I disorders was confirmed using the Structured Clinical Interview for DSMIV Axis I Disorders, version 2.0 (First et al, 1995). None of the participants had a significant medical or neurologic illness, history of loss of consciousness greater than $5 \mathrm{~min}$, or active drug or alcohol dependence. HC subjects also lacked a personal history of an Axis I disorder.

Mean age of BD onset, as defined by subject report of the first incidence of mood symptoms to satisfy DSM-IV criteria for a depressive or manic/hypomanic episode, was 21 years $(\mathrm{SD}=8$ years, range $=11-35$ years $)$. Mean length of $\mathrm{BD}$ illness duration was 18 years $(\mathrm{SD}=10$ years; range $=$ $2-40$ years). Five (25\%) of the BD subjects had experienced past psychotic symptoms that occurred within the context of a manic episode. None of the subjects were psychotic at the time of scan. Two (10\%) of the BD subjects had a history of panic disorder and $14(70 \%)$ had a history of substance abuse or dependence (including alcohol). All were in remission for at least 1 year (range $=1-27$ years), with the exception of one subject who was in remission for 5 months. Average length of time in remission was 11 years. Five $(25 \%)$ of these subjects had a history of alcohol dependence and 2 had additional comorbid substance dependence (1 cocaine and 1 polysubstance dependence). One subject had a history of cannabis dependence. An additional 8 (40\%) BD subjects had a history of substance abuse (4 alcohol and cannabis, 2 alcohol only, 1 cannabis only and 1 abused multiple substances). Eight (40\%) of the BD subjects met past criteria for rapid cycling. Six $(30 \%)$ of the subjects were euthymic at the time of scan, $8(40 \%)$ were depressed, and 5 (25\%) were manic or hypomanic. Six $(30 \%)$ of the BD subjects were unmedicated at the time of scan. Of the remaining 13 subjects, 5 (25\%) were prescribed lithium salts, $8(40 \%)$ an anticonvulsant, $6(30 \%)$ an atypical antipsychotic, $6(30 \%)$ an antidepressant, and 1 (5\%) levothyroxine.

\section{Genotyping}

Blood was collected by venopuncture and frozen at $-20^{\circ} \mathrm{C}$. Samples were thawed and DNA extracted using Puregene kits (Gentra, Minneapolis, Minnesota). The BDNF gene 
polymorphism at position 196 (codon 66), G/A (val/met) was identified using an ABI TaqMan assay (Applied Biosystems, Foster City, California) (Shi et al, 1999).

\section{Acquisition and Processing of Magnetic Resonance Images}

Magnetic resonance imaging (MRI) scans were obtained using a single 1.5-T scanner (GE Signa; General Electric, Milwaukee, Wisconsin). Head position was standardized using canthomeatal landmarks and image parameters set at a 3D sagittal spoiled gradient echo sequence (repetition time, $24 \mathrm{~ms}$; echo time, $5 \mathrm{~ms}$; flip angle, $45^{\circ}$; frequency encoding superior/inferior; no wrap; $256 \times 192$ matrix; field of view, $30 \mathrm{~cm}$; two excitations; slice thickness, $1.2 \mathrm{~mm}$; and 124 contiguous slices).

Hand-tracing of hippocampus region of interest. Prior to tracing of the hippocampus, half of the brain images were flipped in left-right orientation. Personnel blind to subject diagnosis and left-right brain orientation performed the hippocampus delineations. Methods for stripping the skull and segmenting the brain are previously described (Blumberg et al, 2003). Total brain volume (TBV) was calculated as volume of cerebral gray matter plus white matter with interrater intraclass correlation coefficients of 0.999 , as assessed on 10 scans. The hippocampus was defined by manual tracing performed by one of two trained research personnel whose interrater intraclass reliability coefficients were 0.924 for left hippocampus and 0.902 for right hippocampus traced on 10 brains. Tracings were performed in the coronal plane according to methods previously described (Blumberg et al, 2003; Kates et al, 1997; Peterson et al, 2001). Briefly, the anterior of the hippocampus was defined by the slice at which the temporal horn shifts from a lateral to superior position in relation to the hippocampus. The posterior boundary was defined by the slice in which the splenium of the corpus callosum begins to join the fornix. Final tracings were confirmed in orthogonal views.

Three-dimensional mapping of hippocampus morphology. Three-dimensional mapping of the hippocampus was performed using an extended robust point matching (RPM) nonrigid registration algorithm (Duncan et al, 2004; Papademetris et al, 2003) that is part of the Yale BioImage Suite image analysis package (Papademetris et al, 2006). First, all hippocampal tracings were registered to that of a single subject using RPM. An average transformation from all subjects was then used to warp the single subject's right and left hippocampus to generate new synthetic hippocampus tracings whose shape and size were effectively means of the data set. All original subjects' hippocampus tracings $(N=38)$ were then registered to these templates using RPM. Final registrations were verified visually for accuracy, and a map of local expansion or contraction created based on the determinant of the Jacobian of the displacement field generated by each registration (Staib et al, 2006). This analysis produced a Jacobian map where each voxel had a value representing the local volume change required to map an individual subject to the mean template (ie $1=$ no volume change, $>1=$ individual subject is larger than the template, and $<1=$ individual subject is smaller than the template). These Jacobian maps were checked to ensure transformations were free of singularities (ie $|J|<0$ ).

\section{Statistical Analyses}

Hippocampus region of interest analyses. Statistical analyses for region of interest (ROI)-based hippocampus tracings were performed using SAS software, version 9.1 (SAS Institute Inc., Cary, $\mathrm{NC})$. All subjects $(N=38)$ were included in a linear mixed model analysis with group (BD vs $\mathrm{HC}$ ) and BDNF genotype (val/val vs met carriers) (Egan et al, 2003; Hariri et al, 2003) as the between-subjects factors. Hemisphere (left $v s$ right) was included as a withinsubjects exploratory factor and all two- and three-way interactions were tested. Subject was used as the clustering factor. Age and sex were included as covariates based on previous reports implicating these factors in hippocampus volume (Blumberg et al, 2003; Frazier et al, 2005; Pruessner et al, 2001). TBV was included as a covariate to account for general scaling effects. Least square (LS) means were calculated from the mixed model for hippocampus volume and plotted to interpret effects of diagnosis and genotype (Figure 1).

Post hoc analyses were conducted to explore potential main effects of clinical variables within the BD group, including illness onset or duration, history of psychosis, history of substance abuse or dependence (treated as a dichotomous variable), rapid cycling, mood state, presence or absence of medications at the time of scan, and effects of individual classes of psychotropic medications on hippocampus volumes in $\mathrm{BD}$.

Three-dimensional mapping of hippocampus morphology. Three-dimensional mapping methods were used to localize effects of $B D N F$ genotypes within $\mathrm{BD}$ by performing twosample $t$-tests comparing $\mathrm{BD}$ val/val homozygotes with $\mathrm{BD}$ met carriers at all hippocampus voxels. These analyses were performed using the Yale BioImage Suite software package (www.bioimagesuite.org) with morphometric Jacobian

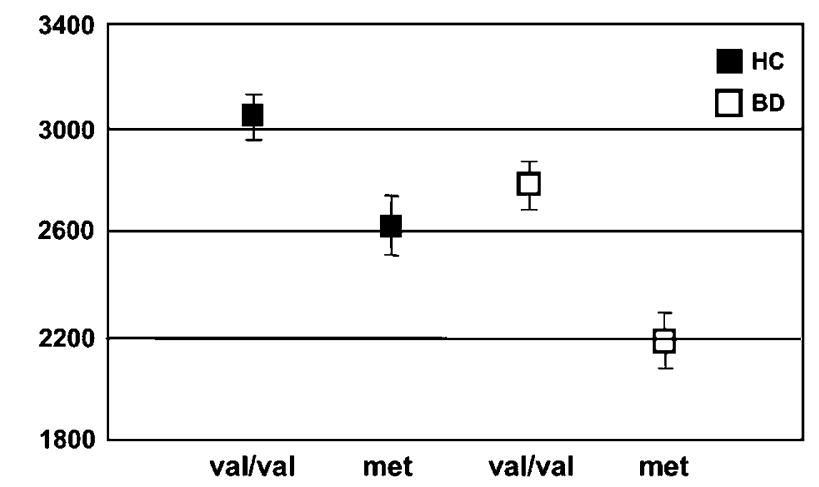

Figure I The graph displays LS means and standard errors for hippocampus volumes by BDNF genetic variation and diagnosis. Volumes were reduced significantly in association with the presence of the met allele and with BD diagnosis. Individuals with BD who carried the BDNF met allele had the smallest hippocampus volumes. Sample sizes for each group are as follows: $\mathrm{HC}$ val/val $\mathrm{N}=12, \mathrm{HC}$ met (val/met genotype) $\mathrm{N}=6$, $\mathrm{BD}$ val/val $N=12$ and $\mathrm{BD}$ met (val/met and met/met) $N=7$. BD, bipolar disorder; $B D N F$, brain-derived neurotrophic growth factor; LS, least square. 
values as the dependent variables. Significant localized effects of $B D N F$ genotype were plotted on a 3D rendering of the mean of the hippocampus tracings for all participants.

\section{RESULTS}

There were no significant differences in sex or genotype distribution between diagnostic groups. There was a significant difference in mean age between diagnostic groups as the $\mathrm{HC}$ group contained significantly younger subjects than the group with $\mathrm{BD}\left(M_{\mathrm{HC}}=28, \mathrm{SD}=12\right.$; $\left.M_{\mathrm{BD}}=40, \mathrm{SD}=9 ; p<0.001\right)$. Within the $\mathrm{BD}$ group, met carriers did not differ from val/val homozygotes on any of the clinical variables measured.

The ROI analyses revealed significant main effects of both genotype $\left(\mathrm{F}_{1,31}=13.3 ; p<0.001\right)$ and group $\left(\mathrm{F}_{1,31}=8.1\right.$; $p<0.008)$ on hippocampus volume. Carriers of the BDNF met allele had significantly smaller LS mean hippocampus volumes than individuals homozygous for the val allele $\left(\mathrm{LSmean}_{m e t}=2433, \mathrm{SE}_{m e t}=115 ; \mathrm{LSmean}_{\text {val }}=2950, \mathrm{SE}_{\text {val }}=\right.$ 86). In addition, the $\mathrm{BD}$ group demonstrated smaller hippocampus volumes than the $\mathrm{HC}$ group $\left(\mathrm{LSmean}_{\mathrm{BD}}=\right.$ 2458, $\left.\mathrm{SE}_{\mathrm{BD}}=100 ; \mathrm{LSmean}_{\mathrm{HC}}=2925, \mathrm{SE}_{\mathrm{HC}}=100\right)$. BD met carriers had the smallest hippocampal volumes compared to $\mathrm{BD}$ val/val homozygotes and $\mathrm{HC}$ subjects $\left(\mathrm{LSmean}_{\mathrm{HC} \text { al }}=\right.$ $3166, \mathrm{SE}=134 ; \mathrm{LSmean}_{\mathrm{HC} \text { et }}=2683, \mathrm{SE}=178 ; \mathrm{LSmean}_{\mathrm{BD} v a l}=$ $2734, \mathrm{SE}=125$; LSmean $_{\mathrm{BD} m e t}=2181, \mathrm{SE}=149$ ) (Figure 1). The ROI analyses of genotype and group remained significant using only the subgroup of European-American subjects $(p<0.001$ and $p<0.01$, respectively). Individual subject data points are illustrated in Supplementary Figure 1. The interaction between genotype and group was not significant. There were also no significant main effects of age, sex, hemisphere, or any of the clinical variables explored on hippocampus volumes $(p>0.12$ for all analyses).

Three-dimensional morphological mapping demonstrated localized decreases in hippocampus volume in $\mathrm{BD}$ met carriers compared to $\mathrm{BD}$ val/val homozygotes within the left anterior hippocampus where two regions of difference were evident ( $p<0.05$, uncorrected). One region contained an area that survived significance of $p<0.0005$ (Figure 2).

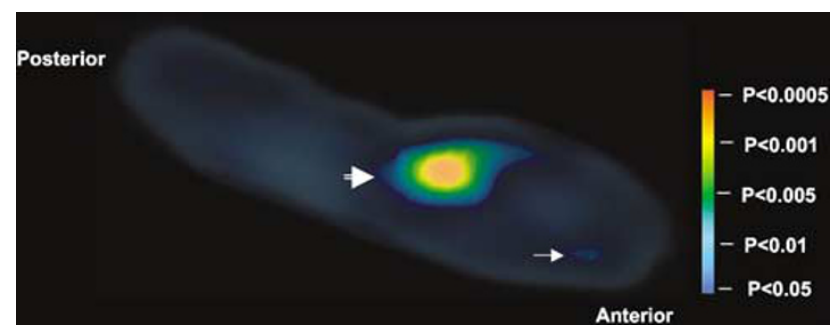

Figure 2 This image demonstrates three-dimensional morphometric mapping of regions of significant difference in $\mathrm{BD} B D N F$ met carriers compared to BD BDNF val/val homozygotes ( $p<0.05$, uncorrected). In the left anterior hippocampus, in addition to a small area of decreased volume (small arrow), there was a more prominent area of decreased volume that included a region at the level of significance of $p<0.0005$ (indicated by the large arrow). BD, bipolar disorder; BDNF, brain-derived neurotrophic growth factor.

\section{DISCUSSION}

In this study, adults with $\mathrm{BD}$ had significantly smaller hippocampus volumes than HC subjects. This decrease in volume is consistent with observed reductions in cellular number and density in postmortem studies of hippocampus in BD. In addition, presence of the BDNF met allele was associated with reduced hippocampus volume in both $\mathrm{HC}$ and BD samples. Hippocampus volume was smallest in the individuals with $\mathrm{BD}$ who carried the BDNF met allele, as compared to $\mathrm{HC}$ subjects and $\mathrm{BD}$ val/val homozygotes. We suggest the BDNF met allele may function as one of several factors that, along with a diagnosis of $\mathrm{BD}$, put the hippocampus beyond a threshold for normal structure and function. Thus, the subgroup with BD that carries the met allele may be a subgroup most vulnerable to hippocampus-related deficits.

The effects of the BNDF met allele in $\mathrm{BD}$ were localized to left anterior hippocampus. This finding is consistent with the neurovegetative, emotional, and cognitive symptoms associated with this disorder. Anterior hippocampus and its nonhuman primate analogue ventral hippocampus (Jay and Witter, 1991; Sasaki et al, 2004) have substantial connections with the hypothalamic-pituitary-adrenal (HPA) axis, amygdala, and prefrontal cortex that are implicated in the above symptoms (Bannerman et al, 2004). Anterior hippocampus activity has been associated with modulation of the HPA axis (Aihara et al, 2007; Colla et al, 2007) and hippocampus neurotrophin expression has been proposed to directly mediate this association (Uys et al, 2006). Behavioral studies demonstrate specialization of ventral or anterior hippocampus in select memory functions in rodents and in both human and nonhuman primates (Colombo et al, 1998; Dolan and Fletcher, 1999; Kjelstrup et al, 2002; Sinnamon et al, 1978; Stevens and Cowey, 1973; Strange et al, 1999). Anterior hippocampus may also be associated with anxiety-related behaviors, such as those seen in post-traumatic stress disorder, which demonstrate reductions in anterior hippocampus activity and volume (Etkin and Wager, 2007; Vythilingam et al, 2005). Differences in anterior hippocampus volume have also been associated with schizophrenia (Bilder et al, 1995; Narr et al, 2004; Pegues et al, 2003). Together, these findings raise questions as to whether individuals with $\mathrm{BD}$ who have decreased anterior hippocampus volume might represent a clinically distinct subgroup within the heterogeneous presentations of $\mathrm{BD}$. One might expect these individuals to demonstrate abnormalities related to anterior hippocampus-based circuitry, including HPA dysfunction, memory impairment, and symptoms of anxiety or psychosis. This spectrum of symptoms may reflect a phenotypic presentation that exists across psychiatric disorders demonstrating a gene-related neuroanatomical abnormality.

Indeed, decreases in hippocampus volume in association with the BDNF met allele are not specific to $\mathrm{BD}$. They have been reported in major depression (Frodl et al, 2007) and schizophrenia (Szeszko et al, 2005). These studies, in addition to our current findings, suggest the BDNF met allele may be associated with hippocampus-related phenotypic features common to several psychiatric diagnoses. Further investigation into $B D N F$-mediated effects may help parse the heterogeneous features of these disorders, as well 
as suggest mechanisms that underlie their common symptoms.

Variation in $B D N F$ genotype may have contributed to differences in hippocampus volume findings among previous MRI studies in BD (Blumberg et al, 2003; Brambilla et al, 2003; Chen et al, 2004a; Dickstein et al, 2005; Frazier et al, 2005; Hauser et al, 2000; Noga et al, 2001; Strakowski et al, 1999). Some studies report the BDNF val allele may be preferentially transmitted in BD (NevesPereira et al, 2002), although this finding is not universally reported (Zhang et al, 2006). There is also evidence that the $B D N F$ met and val alleles may be associated with clinical subgroups within BD (Geller et al, 2004; Green et al, 2006; McIntosh et al, 2007), supporting the hypothesis presence of the val or met alleles may modify different phenotypes within this disorder. McIntosh et al (2007) report greater decreases in temporal lobe volumes in $\mathrm{BD}$ over a 4 -year interval in association with the $B D N F$ met allele, suggesting $B D N F$ variation has dynamic effects on hippocampus volume during adulthood. Although duration of affective illness (Sheline et al, 1999), presence of psychotic symptoms (Strasser et al, 2005), age or stage of development (Blumberg et al, 2003; Frazier et al, 2005; Pruessner et al, 2001) and sex (Frazier et al, 2005; Pruessner et al, 2001) may also influence hippocampus volume, we did not detect significant influences of these factors in this study. However, the group sizes may have limited our power to detect such effects. We also did not detect significant effects of history of substance abuse or dependence on hippocampus volumes, although power may have been limited to detect such effects. Differences in anterior hippocampus volume in association with alcohol dependence have been previously reported (Sullivan et al, 1995). Although this study found no association between lifetime alcohol consumption and hippocampus volume, it is possible that alcohol exposure could have influenced our findings.

Our results may have implications for clinical interventions in the treatment of $\mathrm{BD}$ as serotonergic antidepressant medications, mood stabilizers such as lithium and valproic acid, and nonpharmacological treatments such as exercise have been shown to upregulate $B D N F$ and its associated neurotrophic effects in hippocampus (Duman and Monteggia, 2006; Frey et al, 2006; Fukumoto et al, 2001; Malberg et al, 2000; Manji et al, 2000; Santarelli et al, 2003). Lithium has also been associated with increases in hippocampus volume in persons with BD (Bearden et al, 2008; Yucel et al, 2007), including increases specifically within the hippocampus head (Yucel et al, 2008). These reports suggest persons with $\mathrm{BD}$ who carry the BDNF met allele might benefit most from treatments mediated by $B D N F$-related mechanisms. However, it is also possible that BDNF met carriers may be more resistant to these treatments if ability to mount a $B D N F$-related response is diminished in these individuals. Since the BDNF met allele has been associated with deficits in recovery from stress (Gould et al, 1997, 1998; Magarinos et al, 1996), it may be alternative strategies, such as stress and anxiety reduction, may be needed to reverse anterior hippocampus abnormalities. In addition, interaction between $B D N F$ and serotonin proteins are implicated in neural development and plasticity (Duman, 2002; Peng et al, 2008; Sairanen et al, 2005). This suggests interaction of $B D N F$ - and serotonin-related genes, such as the serotonin transporter gene polymorphisms (5-HTTLPR) may modulate hippocampus morphology in mood disorders. Sample sizes limited investigation into interactions between $B D N F$ and 5-HTTLPR in this study, however future study of these interactions is warranted.

In sum, this study of the val66met polymorphism provides preliminary evidence that variation in $B N D F$ has the potential to influence hippocampus structure in $\mathrm{BD}$, and carriers of the met allele may be a subgroup within $\mathrm{BD}$ more vulnerable to hippocampus-related deficits. Potential influence of the BDNF val66met polymorphism on hippocampus provides one model of a molecular mechanism that may contribute to clinical heterogeneity within $\mathrm{BD}$. Improved understanding of the role of $B D N F$ in $\mathrm{BD}$ may help to identify a subset of patients who would most benefit from interventions that can target $B D N F$-related mechanisms and modify BDNF expression.

\section{ACKNOWLEDGEMENTS}

This article is dedicated to Ms Kathleen Colonese who was devoted to helping those suffering from psychiatric illnesses and whose kindness to colleagues and participants alike touched us all. We give thanks to all of the participants in this study, and hope that this work may one day contribute to helping those living with bipolar disorder. We thank $\mathrm{Dr}$ Alark Joshi for his expertise in medical imaging and for his help in generating Figure 2; Hedy Sarofin RTRMR and Terry Hickey RTRMRN for their technical expertise; Ann Marie Lacobelle for genotyping assistance; the nurses of the Biostudies Unit Angelina M Genovese RNC, MBA, Elizabeth O'Donnell RN, and Brenda Breault RN, BSN; and the research subjects for their participation. We also acknowledge the help and support of all members of the Mood Disorders Laboratory at Yale, including Ms Linda Spencer, Ms Gina Williams, and Mr Thomas Flanagan. HPB was supported by research grants from the Department of Veterans Affairs Research Career Development, Merit Review (HPB), and Research Enhancement Award Program (REAP) Awards (LGC, HPB, RSD, JG); the National Institute of Mental Health R01MH070902 (HPB), T32MH14276 (LGC and RSD), and R01EB006494 (XP); the National Alliance for Research on Schizophrenia and Depression (Great Neck, NY) (HPB); The Attias Family Foundation (HPB); and The Ethel $F$ Donaghue Women's Investigator Program at Yale (New Haven, CT) (HPB).

\section{DISCLOSURE/CONFLICT OF INTEREST}

The authors declare that except for income received from primary employers no financial support or compensation has been received from any individual or corporate entity over the past 3 years for research or professional service aside from those listed below and there are no personal financial holdings that could be perceived as constituting a potential conflict of interests.

Dr Blumberg: consultant: Pfizer Inc.

Dr Gelernter has received financial support or compensation for the following: related to consultation for Columbia University, the Thailand Center for Excellence for Life Sciences (TCELS), the University of CT Health Center, NIH, 
and Faegre \& Benson; related to grant reviews for the National Institutes of Health; and related to academic lectures and editorial functions in various scientific venues (including the ACNP).

Dr Duman has received consulting or speaker compensation from Psychogenics, Taisho, Lilly, Wyeth-Ayerst, Lundbeck, Organon, Sepracor, and Takeda.

\section{REFERENCES}

Aihara M, Ida I, Yuuki N, Oshima A, Kumano H, Takahashi K et al (2007). HPA axis dysfunction in unmedicated major depressive disorder and its normalization by pharmacotherapy correlates with alteration of neural activity in prefrontal cortex and limbic/ paralimbic regions. Psychiatry Res 155: 245-256.

Altshuler LL, Bartzokis G, Grieder T, Curran J, Jimenez T, Leight $\mathrm{K}$ et al (2000). An MRI study of temporal lobe structures in men with bipolar disorder or schizophrenia. Biol Psychiatry 48: 147-162.

Bannerman DM, Rawlins JN, McHugh SB, Deacon RM, Yee BK, Bast $\mathrm{T}$ et al (2004). Regional dissociations within the hippocampus-memory and anxiety. Neurosci Biobehav Rev 28: 273-283.

Bearden CE, Thompson PM, Dutton RA, Frey BN, Peluso MA, Nicoletti $M$ et al (2008). Three-dimensional mapping of hippocampal anatomy in unmedicated and lithium-treated patients with bipolar disorder. Neuropsychopharmacology 33: 1229-1238.

Benes FM, Kwok EW, Vincent SL, Todtenkopf MS (1998). A reduction of nonpyramidal cells in sector CA2 of schizophrenics and manic depressives. Biol Psychiatry 44: 88-97.

Bennett GD, Wlodarczyk B, Calvin JA, Craig JC, Finnell RH (2000). Valproic acid-induced alterations in growth and neurotrophic factor gene expression in murine embryos (corrected). Reprod Toxicol 14: 1-11.

Bertolino A, Frye M, Callicott JH, Mattay VS, Rakow R, SheltonRepella J et al (2003). Neuronal pathology in the hippocampal area of patients with bipolar disorder: a study with proton magnetic resonance spectroscopic imaging. Biol Psychiatry 53: 906-913.

Bielau H, Trubner K, Krell D, Agelink MW, Bernstein HG, Stauch R et al (2005). Volume deficits of subcortical nuclei in mood disorders. A postmortem study. Eur Arch Psychiatry Clin Neurosci 255: 401-412.

Bilder RM, Bogerts B, Ashtari M, Wu H, Alvir JM, Jody D et al (1995). Anterior hippocampal volume reductions predict frontal lobe dysfunction in first episode schizophrenia. Schizophr Res 17: 47-58.

Blumberg HP, Kaufman J, Martin A, Whiteman R, Zhang JH, Gore JC et al (2003). Amygdala and hippocampal volumes in adolescents and adults with bipolar disorder. Arch Gen Psychiatry 60: 1201-1208.

Brambilla P, Harenski K, Nicoletti M, Sassi RB, Mallinger AG, Frank E et al (2003). MRI investigation of temporal lobe structures in bipolar patients. J Psychiatr Res 37: 287-295.

Bueller JA, Aftab M, Sen S, Gomez-Hassan D, Burmeister M, Zubieta JK (2006). BDNF Val66Met allele is associated with reduced hippocampal volume in healthy subjects. Biol Psychiatry 59: $812-815$

Cavanagh JT, Van Beck M, Muir W, Blackwood DH (2002). Casecontrol study of neurocognitive function in euthymic patients with bipolar disorder: an association with mania. Br J Psychiatry 180: $320-326$.

Chambers JS, Perrone-Bizzozero NI (2004). Altered myelination of the hippocampal formation in subjects with schizophrenia and bipolar disorder. Neurochem Res 29: 2293-2302.

Chang K, Karchemskiy A, Barnea-Goraly N, Garrett A, Simeonova DI, Reiss A (2005). Reduced amygdalar gray matter volume in familial pediatric bipolar disorder. J Am Acad Child Adolesc Psychiatry 44: 565-573.

Chen B, Dowlatshahi D, MacQueen GM, Wang JF, Young LT (2001). Increased hippocampal BDNF immunoreactivity in subjects treated with antidepressant medication. Biol Psychiatry 50: $260-265$.

Chen BK, Sassi R, Axelson D, Hatch JP, Sanches M, Nicoletti M et al (2004a). Cross-sectional study of abnormal amygdala development in adolescents and young adults with bipolar disorder. Biol Psychiatry 56: 399-405.

Chen ZY, Patel PD, Sant G, Meng CX, Teng KK, Hempstead BL et al (2004b). Variant brain-derived neurotrophic factor (BDNF) (Met66) alters the intracellular trafficking and activity-dependent secretion of wild-type BDNF in neurosecretory cells and cortical neurons. J Neurosci 24: 4401-4411.

Clark L, Iversen SD, Goodwin GM (2001). A neuropsychological investigation of prefrontal cortex involvement in acute mania. Am J Psychiatry 158: 1605-1611.

Colla M, Kronenberg G, Deuschle M, Meichel K, Hagen T, Bohrer $M$ et al (2007). Hippocampal volume reduction and HPA-system activity in major depression. J Psychiatr Res 41: 553-560.

Colombo M, Fernandez T, Nakamura K, Gross CG (1998). Functional differentiation along the anterior-posterior axis of the hippocampus in monkeys. J Neurophysiol 80: 1002-1005.

Cunha AB, Frey BN, Andreazza AC, Goi JD, Rosa AR, Goncalves CA et al (2006). Serum brain-derived neurotrophic factor is decreased in bipolar disorder during depressive and manic episodes. Neurosci Lett 398: 215-219.

Deckersbach T, Savage CR, Reilly-Harrington N, Clark L, Sachs G, Rauch SL (2004). Episodic memory impairment in bipolar disorder and obsessive-compulsive disorder: the role of memory strategies. Bipolar Disord 6: 233-244.

Deicken RF, Pegues MP, Anzalone S, Feiwell R, Soher B (2003). Lower concentration of hippocampal $N$-acetylaspartate in familial bipolar I disorder. Am J Psychiatry 160: 873-882.

Dickstein DP, Milham MP, Nugent AC, Drevets WC, Charney DS, Pine DS et al (2005). Frontotemporal alterations in pediatric bipolar disorder: results of a voxel-based morphometry study. Arch Gen Psychiatry 62: 734-741.

Dolan RJ, Fletcher PF (1999). Encoding and retrieval in human medial temporal lobes: an empirical investigation using functional magnetic resonance imaging (fMRI). Hippocampus 9: 25-34.

Dowlatshahi D, MacQueen G, Wang JF, Chen B, Young LT (2000). Increased hippocampal supragranular Timm staining in subjects with bipolar disorder. Neuroreport 11: 3775-3778.

Duman RS (2002). Synaptic plasticity and mood disorders. Mol Psychiatry 7(Suppl 1): S29-S34.

Duman RS, Charney DS (1999). Cell atrophy and loss in major depression. Biol Psychiatry 45: 1083-1084.

Duman RS, Heninger GR, Nestler EJ (1997). A molecular and cellular theory of depression. Arch Gen Psychiatry 54: 597-606.

Duman RS, Monteggia LM (2006). A neurotrophic model for stress-related mood disorders. Biol Psychiatry 59: 1116-1127.

Duncan JS, Papademetris X, Yang J, Jackowski M, Zeng X, Staib LH (2004). Geometric strategies for neuroanatomic analysis from MRI. Neuroimage 23(Suppl 1): S34-S45.

Egan MF, Kojima M, Callicott JH, Goldberg TE, Kolachana BS, Bertolino A et al (2003). The BDNF val66met polymorphism affects activity-dependent secretion of BDNF and human memory and hippocampal function. Cell 112: 257-269.

Etkin A, Wager TD (2007). Functional neuroimaging of anxiety: a meta-analysis of emotional processing in PTSD, social anxiety disorder, and specific phobia. Am J Psychiatry 164: 1476-1488.

Fatemi SH, Earle JA, Stary JM, Lee S, Sedgewick J (2001). Altered levels of the synaptosomal associated protein SNAP-25 in hippocampus of subjects with mood disorders and schizophrenia. Neuroreport 12: 3257-3262. 
First MB, Spitzer RL, Gibbon M, Williams JBW (1995). Structured Clinical Interview for DSM-IV Axis I \& II Disorders (Version 2.0). New York State Psychiatric Institute: New York, NY.

Frazier JA, Chiu S, Breeze JL, Makris N, Lange N, Kennedy DN et al (2005). Structural brain magnetic resonance imaging of limbic and thalamic volumes in pediatric bipolar disorder. $A m J$ Psychiatry 162: 1256-1265.

Frey BN, Andreazza AC, Cereser KM, Martins MR, Valvassori SS, Reus GZ et al (2006). Effects of mood stabilizers on hippocampus BDNF levels in an animal model of mania. Life Sci 79: 281-286.

Frodl T, Schule C, Schmitt G, Born C, Baghai T, Zill P et al (2007). Association of the brain-derived neurotrophic factor Val66Met polymorphism with reduced hippocampal volumes in major depression. Arch Gen Psychiatry 64: 410-416.

Fukumoto T, Morinobu S, Okamoto Y, Kagaya A, Yamawaki S (2001). Chronic lithium treatment increases the expression of brain-derived neurotrophic factor in the rat brain. Psychopharmacology (Berl) 158: 100-106.

Geller B, Badner JA, Tillman R, Christian SL, Bolhofner K, Cook Jr EH (2004). Linkage disequilibrium of the brain-derived neurotrophic factor Val66Met polymorphism in children with a prepubertal and early adolescent bipolar disorder phenotype. Am J Psychiatry 161: 1698-1700.

Glahn DC, Bearden CE, Caetano S, Fonseca M, Najt P, Hunter K et al (2005). Declarative memory impairment in pediatric bipolar disorder. Bipolar Disord 7: 546-554.

Gould E, McEwen BS, Tanapat P, Galea LA, Fuchs E (1997). Neurogenesis in the dentate gyrus of the adult tree shrew is regulated by psychosocial stress and NMDA receptor activation. J Neurosci 17: 2492-2498.

Gould E, Tanapat P, McEwen BS, Flugge G, Fuchs E (1998). Proliferation of granule cell precursors in the dentate gyrus of adult monkeys is diminished by stress. Proc Natl Acad Sci USA 95: $3168-3171$.

Gourovitch ML, Torrey EF, Gold JM, Randolph C, Weinberger DR, Goldberg TE (1999). Neuropsychological performance of monozygotic twins discordant for bipolar disorder. Biol Psychiatry 45: 639-646.

Green EK, Raybould R, Macgregor S, Hyde S, Young AH, O'Donovan MC et al (2006). Genetic variation of brain-derived neurotrophic factor (BDNF) in bipolar disorder: case-control study of over 3000 individuals from the UK. Br J Psychiatry 188: 21-25.

Hariri AR, Goldberg TE, Mattay VS, Kolachana BS, Callicott JH, Egan MF et al (2003). Brain-derived neurotrophic factor val66met polymorphism affects human memory-related hippocampal activity and predicts memory performance. J Neurosci 23: 6690-6694.

Hashimoto R, Takei N, Shimazu K, Christ L, Lu B, Chuang DM (2002). Lithium induces brain-derived neurotrophic factor and activates TrkB in rodent cortical neurons: an essential step for neuroprotection against glutamate excitotoxicity. Neuropharmacology 43: 1173-1179.

Hauser P, Altshuler LL, Berrettini W, Dauphinais ID, Gelernter J, Post RM (1989). Temporal lobe measurement in primary affective disorder by magnetic resonance imaging. J Neuropsychiatry Clin Neurosci 1: 128-134.

Hauser P, Matochik J, Altshuler LL, Denicoff KD, Conrad A, Li X et al (2000). MRI-based measurements of temporal lobe and ventricular structures in patients with bipolar I and bipolar II disorders. J Affect Disord 60: 25-32.

Jay TM, Witter MP (1991). Distribution of hippocampal CA1 and subicular efferents in the prefrontal cortex of the rat studied by means of anterograde transport of Phaseolus vulgaris-leucoagglutinin. J Comp Neurol 313: 574-586.

Kates WR, Abrams MT, Kaufmann WE, Breiter SN, Reiss AL (1997). Reliability and validity of MRI measurement of the amygdala and hippocampus in children with fragile $\mathrm{X}$ syndrome. Psychiatry Res 75: 31-48.

Keri S, Kelemen O, Benedek G, Janka Z (2001). Different trait markers for schizophrenia and bipolar disorder: a neurocognitive approach. Psychol Med 31: 915-922.

Kjelstrup KG, Tuvnes FA, Steffenach HA, Murison R, Moser EI, Moser MB (2002). Reduced fear expression after lesions of the ventral hippocampus. Proc Natl Acad Sci USA 99: 10825-10830.

Knable MB, Barci BM, Webster MJ, Meador-Woodruff J, Torrey EF (2004). Molecular abnormalities of the hippocampus in severe psychiatric illness: postmortem findings from the Stanley Neuropathology Consortium. Mol Psychiatry 9: 609-620, 544.

Konradi C, Eaton M, MacDonald ML, Walsh J, Benes FM, Heckers $S$ (2004). Molecular evidence for mitochondrial dysfunction in bipolar disorder. Arch Gen Psychiatry 61: 300-308.

Law AJ, Deakin JF (2001). Asymmetrical reductions of hippocampal NMDAR1 glutamate receptor mRNA in the psychoses. Neuroreport 12: 2971-2974.

MacDonald ML, Naydenov A, Chu M, Matzilevich D, Konradi C (2006). Decrease in creatine kinase messenger RNA expression in the hippocampus and dorsolateral prefrontal cortex in bipolar disorder. Bipolar Disord 8: 255-264.

Magarinos AM, McEwen BS, Flugge G, Fuchs E (1996). Chronic psychosocial stress causes apical dendritic atrophy of hippocampal CA3 pyramidal neurons in subordinate tree shrews. J Neurosci 16: 3534-3540.

Maisonpierre PC, Belluscio L, Friedman B, Alderson RF, Wiegand SJ, Furth ME et al (1990). NT-3, BDNF, and NGF in the developing rat nervous system: parallel as well as reciprocal patterns of expression. Neuron 5: 501-509.

Malberg JE, Eisch AJ, Nestler EJ, Duman RS (2000). Chronic antidepressant treatment increases neurogenesis in adult rat hippocampus. J Neurosci 20: 9104-9110.

Manji HK, Moore GJ, Rajkowska G, Chen G (2000). Neuroplasticity and cellular resilience in mood disorders. Mol Psychiatry 5: 578-593.

McIntosh AM, Moorhead TW, McKirdy J, Sussmann JE, Hall J, Johnstone EC et al (2007). Temporal grey matter reductions in bipolar disorder are associated with the BDNF Val66Met polymorphism. Mol Psychiatry 12: 902-903.

Narr KL, Thompson PM, Szeszko P, Robinson D, Jang S, Woods $\mathrm{RP}$ et al (2004). Regional specificity of hippocampal volume reductions in first-episode schizophrenia. Neuroimage 21: 1563-1575.

Neumeister A, Yuan P, Young TA, Bonne O, Luckenbaugh DA, Charney DS et al (2005). Effects of tryptophan depletion on serum levels of brain-derived neurotrophic factor in unmedicated patients with remitted depression and healthy subjects. Am J Psychiatry 162: 805-807.

Neves-Pereira M, Mundo E, Muglia P, King N, Macciardi F, Kennedy JL (2002). The brain-derived neurotrophic factor gene confers susceptibility to bipolar disorder: evidence from a family-based association study. Am J Hum Genet 71: 651-655.

Nibuya M, Morinobu S, Duman RS (1995). Regulation of BDNF and trkB mRNA in rat brain by chronic electroconvulsive seizure and antidepressant drug treatments. J Neurosci 15: 7539-7547.

Noga JT, Vladar K, Torrey EF (2001). A volumetric magnetic resonance imaging study of monozygotic twins discordant for bipolar disorder. Psychiatry Res 106: 25-34.

Papademetris X, Jackowski AP, Schultz RT, Staib LH, Duncan JS (2003). Non-rigid brain registration using extended robust point matching for composite multisubject fmri analysis. MICCAI 2: 788-795.

Papademetris X, Jackowski M, Rajeevan N, Constable RT, Staib LH (2006). BioImage suite: an integrated medical image analysis suite. Section of Bioimaging Sciences, Yale School of Medicine.

Pavuluri MN, Schenkel LS, Aryal S, Harral EM, Hill SK, Herbener ES et al (2006). Neurocognitive function in unmedicated manic 
and medicated euthymic pediatric bipolar patients. Am J Psychiatry 163: 286-293.

Pegues MP, Rogers LJ, Amend D, Vinogradov S, Deicken RF (2003). Anterior hippocampal volume reduction in male patients with schizophrenia. Schizophr Res 60: 105-115.

Peng $\mathrm{CH}$, Chiou SH, Chen SJ, Chou YC, Ku HH, Cheng CK et al (2008). Neuroprotection by imipramine against lipopolysaccharide-induced apoptosis in hippocampus-derived neural stem cells mediated by activation of BDNF and the MAPK pathway. Eur Neuropsychopharmacol 18: 128-140.

Peterson BS, Staib L, Scahill L, Zhang H, Anderson C, Leckman JF et al (2001). Regional brain and ventricular volumes in Tourette syndrome. Arch Gen Psychiatry 58: 427-440.

Pezawas L, Verchinski BA, Mattay VS, Callicott JH, Kolachana BS, Straub RE et al (2004). The brain-derived neurotrophic factor val66met polymorphism and variation in human cortical morphology. J Neurosci 24: 10099-10102.

Pruessner JC, Collins DL, Pruessner M, Evans AC (2001). Age and gender predict volume decline in the anterior and posterior hippocampus in early adulthood. J Neurosci 21: 194-200.

Rosoklija G, Toomayan G, Ellis SP, Keilp J, Mann JJ, Latov N et al (2000). Structural abnormalities of subicular dendrites in subjects with schizophrenia and mood disorders: preliminary findings. Arch Gen Psychiatry 57: 349-356.

Sairanen M, Lucas G, Ernfors P, Castren M, Castren E (2005). Brain-derived neurotrophic factor and antidepressant drugs have different but coordinated effects on neuronal turnover, proliferation, and survival in the adult dentate gyrus. J Neurosci 25: $1089-1094$.

Santarelli L, Saxe M, Gross C, Surget A, Battaglia F, Dulawa S et al (2003). Requirement of hippocampal neurogenesis for the behavioral effects of antidepressants. Science 301: 805-809.

Sasaki M, Tohyama K, Matsunaga S, Nakamura M, Tomizawa N, Inoue $\mathrm{T}$ et al (2004). MRI identification of dorsal hippocampus homologue in human brain. Neuroreport 15: 2173-2176.

Sax KW, Strakowski SM, Zimmerman ME, DelBello MP, Keck Jr PE, Hawkins JM (1999). Frontosubcortical neuroanatomy and the continuous performance test in mania. Am J Psychiatry 156: 139-141.

Sheline YI, Sanghavi M, Mintun MA, Gado MH (1999). Depression duration but not age predicts hippocampal volume loss in medically healthy women with recurrent major depression. J Neurosci 19: 5034-5043.

Shi MM, Myrand SP, Bleavins MR, de la Iglesia FA (1999). High throughput genotyping for the detection of a single nucleotide polymorphism in $\mathrm{NAD}(\mathrm{P}) \mathrm{H}$ quinone oxidoreductase (DT diaphorase) using TaqMan probes. Mol Pathol 52: 295-299.

Sinnamon HM, Freniere S, Kootz J (1978). Rat hippocampus and memory for places of changing significance. J Comp Physiol Psychol 92: 142-155.

Staib L, Jackowski M, Papademetris X (2006). Brain shape characterization from deformation. ISBI 1140-1143.

Stevens R, Cowey A (1973). Effects of dorsal and ventral hippocampal lesions on spontaneous alternation, learned alternation and probability learning in rats. Brain Res 52: 203-224.

Strakowski SM, DelBello MP, Sax KW, Zimmerman ME, Shear PK, Hawkins JM et al (1999). Brain magnetic resonance imaging of structural abnormalities in bipolar disorder. Arch Gen Psychiatry 56: $254-260$.
Strange BA, Fletcher PC, Henson RN, Friston KJ, Dolan RJ (1999). Segregating the functions of human hippocampus. Proc Natl Acad Sci USA 96: 4034-4039.

Strasser HC, Lilyestrom J, Ashby ER, Honeycutt NA, Schretlen DJ, Pulver AE et al (2005). Hippocampal and ventricular volumes in psychotic and nonpsychotic bipolar patients compared with schizophrenia patients and community control subjects: a pilot study. Biol Psychiatry 57: 633-639.

Sullivan EV, Marsh L, Mathalon DH, Lim KO, Pfefferbaum A (1995). Anterior hippocampal volume deficits in nonamnesic, aging chronic alcoholics. Alcohol Clin Exp Res 19: 110-122.

Swayze II VW, Andreasen NC, Alliger RJ, Yuh WT, Ehrhardt JC (1992). Subcortical and temporal structures in affective disorder and schizophrenia: a magnetic resonance imaging study. Biol Psychiatry 31: 221-240.

Sweeney JA, Kmiec JA, Kupfer DJ (2000). Neuropsychologic impairments in bipolar and unipolar mood disorders on the CANTAB neurocognitive battery. Biol Psychiatry 48: 674-684.

Szeszko PR, Lipsky R, Mentschel C, Robinson D, Gunduz-Bruce H, Sevy S et al (2005). Brain-derived neurotrophic factor val66met polymorphism and volume of the hippocampal formation. $\mathrm{Mol}$ Psychiatry 10: 631-636.

Thoenen H (1995). Neurotrophins and neuronal plasticity. Science 270: 593-598.

Uys JD, Marais L, Faure J, Prevoo D, Swart P, Mohammed AH et al (2006). Developmental trauma is associated with behavioral hyperarousal, altered HPA axis activity, and decreased hippocampal neurotrophin expression in the adult rat. Ann NY Acad Sci 1071: 542-546.

van Gorp WG, Altshuler L, Theberge DC, Mintz J (1999). Declarative and procedural memory in bipolar disorder. Biol Psychiatry 46: 525-531.

Velakoulis D, Pantelis C, McGorry PD, Dudgeon P, Brewer W, Cook $\mathrm{M}$ et al (1999). Hippocampal volume in first-episode psychoses and chronic schizophrenia: a high-resolution magnetic resonance imaging study. Arch Gen Psychiatry 56: 133-141.

Vythilingam M, Luckenbaugh DA, Lam T, Morgan III CA, Lipschitz D, Charney DS et al (2005). Smaller head of the hippocampus in Gulf War-related posttraumatic stress disorder. Psychiatry Res 139: 89-99.

Wolfe J, Granholm E, Butters N, Saunders E, Janowsky D (1987). Verbal memory deficits associated with major affective disorders: a comparison of unipolar and bipolar patients. J Affect Disord 13: 83-92.

Yucel K, McKinnon MC, Taylor VH, Macdonald K, Alda M, Young LT et al (2007). Bilateral hippocampal volume increases after long-term lithium treatment in patients with bipolar disorder: a longitudinal MRI study. Psychopharmacology (Berl) 195: 357-367.

Yucel K, Taylor VH, McKinnon MC, Macdonald K, Alda M, Young LT et al (2008). Bilateral hippocampal volume increase in patients with bipolar disorder and short-term lithium treatment. Neuropsychopharmacology 33: 361-367.

Zhang H, Ozbay F, Lappalainen J, Kranzler HR, van Dyck CH, Charney DS et al (2006). Brain derived neurotrophic factor (BDNF) gene variants and Alzheimer's disease, affective disorders, posttraumatic stress disorder, schizophrenia, and substance dependence. Am J Med Genet B Neuropsychiatr Genet 141: 387-393.

Supplementary Information accompanies the paper on the Neuropsychopharmacology website (http://www.nature.com/npp) 